\title{
Annual performance analysis of the PV/T system for the heat demand of a low-energy single-family building
}

\author{
Alina Żabnieńska-Góra, Navid Khordehgah and Hussam Jouhara \\ College of Engineering, Design and Physical Sciences, Brunel University London, UB8 3PH, \\ UK \\ *Corresponding author: e-mail: hussam.jouhara@brunel.ac.uk
}

\begin{abstract}
The interest in the energy efficiency of buildings and the integration of new technologies to reduce the heating and cooling loads through the building envelope is not new. The European Union (EU) is committed to decarbonising its building stock as almost $50 \%$ of the Union's final energy consumption is for heating and cooling, of which $80 \%$ is used in buildings. The article analysis the performance of a PV/T system (with a heat mat) for the heat demand of a lowenergy two-zone, single-family building during the year. For this purpose, a building model was built in TRNSYS using Type 56 and TRNbuild in two variants of heating (internal - as reference and external). Then the building model was connected to a mechanical ventilation system providing heating during winter for which the heat source is a PV/T system to demonstrate if the heating requirements for the household can be provided during different seasons of the year. Additionally, it was indicated how much energy consumption reduction can be obtained in comparison to the case when a heating unit is used.
\end{abstract}

Keywords: performance of a PV/T system, building model, TRNSYS simulation.

\section{Introduction}

The European Union is facing several important problems. One of them is the energy economy of national and European policies [1]. According to the Energy Performance of Buildings Directive 2018/844 (EPBD) [2], which entered into force in 2018, building stock is responsible for about $36 \%$ of all $\mathrm{CO}_{2}$ emissions. European Union commits itself to further reducing greenhouse gas emissions by at least $40 \%$ by 2030 compared to 1990 and according to Energy Roadmap 2050 [3] to 80-95\% below 1990 levels by 2050. The Directive requires Member 
States to develop long-term renovation strategies to support the renovation of residential and non-residential buildings with the aim of making them highly energy-efficient and low-carbon buildings by 2050 . At the same time, increasing the share of renewable energy in total energy consumption supports safe and sustainable energy systems and will contribute to reducing the building operating costs. It should be remembered that the reasons for high costs of using buildings are excessive heat losses caused by poor insulation of external partitions, leaky windows and low efficiency of heating systems.

In recent years, many European countries have introduced legislation and appropriate standards for technical equipment of buildings, related energy savings and thermal insulation, with regards to buildings design, constructed and rebuilt. These legislation aims to increase the efficiency of energy systems while reducing the energy demand for heating and cooling. There are large differences in the building shell performance of the different European countries, however, it is sure that the building shell of newer buildings are much better than that of older buildings.

On the theoretical basis of the heat loss calculation is the fact that the exchange of thermal energy between the systems can take place through conduction, convection and radiation. Most of the heat exchange with the outside environment through the building envelope takes place through conduction, described by Fourier law. Fourier's law states that the density of the conducted heat stream is directly proportional to the temperature gradient:

$$
\vec{q}=-\lambda \operatorname{grad} T
$$

Where $\vec{q}$ is heat stream density vector $\left[\mathrm{W} / \mathrm{m}^{2}\right], \lambda$ is thermal conductivity $[\mathrm{W} / \mathrm{mK}], \mathrm{T}$ is temperature $[\mathrm{K}]$ and grad - is a differential operator (in the Cartesian coordinate system: $\left.\operatorname{grad} T=\frac{\delta T}{\delta x} \bar{l}+\frac{\delta T}{\delta y} \bar{J}+\frac{\delta T}{\delta z} \bar{k}\right)$, which acts on the field. The scalar, in this case the temperature field, assigns it a corresponding vector field. In this case, the heat flux density field. The gradient indicates the direction and return of the greatest increase in value the fields it operates on, such as temperature fields. A minus sign appears in the vector record of Fourier's right because the return of the heat stream density vector is in the direction of temperature drop and the return of the temperature gradient vector is directed in the opposite direction (from lower to higher temperature). 
The thermal transmittance of a single material or an assembly such as a wall or window is expressed as a $\mathrm{U}$-value. The currently used $\mathrm{U}$-value $\left(\mathrm{W} / \mathrm{m}^{2} \mathrm{~K}\right)$ determines the heat flux given in watts, which at a temperature difference of 1 kelvin penetrates through a partition of $1 \mathrm{~m}^{2}$. The required U-value will depend on the location of the project, type of building (domestic or nondomestic) and the application (floor, wall or roof). The Table 1 present the U-values in the following years for new buildings in England according to CIBSE Guide A 2015 [4] and in Poland according to national regulations in force [5]. The values shown in the Table 1 illustrates how the regulations for new buildings have changed in the following years. It is worth remembering that old buildings have much higher heat transfer coefficients and thus higher demand for heat energy and operating costs.

Tables 1. Comparison of U-values in Poland and UK

\begin{tabular}{|l|c|c|c|c|c|}
\hline \multirow{2}{*}{$\begin{array}{l}\text { Building } \\
\text { Section }\end{array}$} & \multicolumn{3}{|c|}{ Poland } & \multicolumn{2}{c|}{ UK } \\
\cline { 2 - 6 } & 2014 & 2017 & 2021 & 2015 & 2020 \\
\hline $\begin{array}{l}\text { External } \\
\text { wall }\end{array}$ & 0.25 & 0.23 & 0.20 & 0.35 & 0.16 \\
\hline Floor & 0.3 & 0.3 & 0.3 & 0.24 & 0.11 \\
\hline Roof & 0.20 & 0.18 & 0.15 & 0.25 & 0.11 \\
\hline Window & 1.3 & 1.1 & 0.9 & 2.2 & 0.9 \\
\hline Door & 1.7 & 1.5 & 1.3 & 0.33 & 0.11 \\
\hline
\end{tabular}

According to the standard [6] U value in the simplified calculation method is described as:

$$
U=\frac{1}{R_{\text {tot }}}
$$

Where:

$\mathrm{U}$ is the thermal transmittance $(\mathrm{W} /(\mathrm{m} 2 \cdot \mathrm{K}))$;

Rtot is the total thermal resistance $(\mathrm{m} 2 \cdot \mathrm{K} / \mathrm{W})$.

Total thermal resistance of a plane building component consisting of thermally homogeneous layers perpendicular to the heat flow can be express as:

$$
R_{\text {tot }}=R_{\text {si }}+R_{1}+R_{2}+\cdots+R_{n}+R_{\text {se }}
$$

where:

$\mathrm{R}_{\text {tot }}$ is the total thermal resistance $\left(\mathrm{m}^{2} \cdot \mathrm{K} / \mathrm{W}\right)$;

$\mathrm{R}_{\mathrm{si}}$ is the internal surface resistance $\left(\mathrm{m}^{2} \cdot \mathrm{K} / \mathrm{W}\right)$; 
$\mathrm{R}_{1}, \mathrm{R}_{2} \ldots \mathrm{Rn}$ are the design thermal resistances of each layer $\left(\mathrm{m}^{2} \cdot \mathrm{K} / \mathrm{W}\right)$;

$\mathrm{R}_{\mathrm{se}}$ is the external surface resistance $\left(\mathrm{m}^{2} \cdot \mathrm{K} / \mathrm{W}\right)$.

If thermal conductivity of the material $\lambda(\mathrm{W} /(\mathrm{m} \cdot \mathrm{K}))$ and the thickness of the material layer in the component $\mathrm{d}(\mathrm{m})$ is given the thermal resistance of the layer can be described as:

$$
\mathrm{R}=\frac{\mathrm{d}}{\lambda}
$$

The density of thermal flux (q) flowing through the partition with the heat transfer coefficient $\mathrm{U}$, separating the compartment with design temperature $t_{i}$ from the outdoor air with temperature $t_{e}$ can be determined from the formula:

$$
\mathrm{q}=\mathrm{U}\left(\mathrm{t}_{\mathrm{i}-\mathrm{te}}\right)
$$

As a result of the flow of a thermal flux of density (q), temperature drops are formed on individual layers of a homogeneous multilayer flat partition, being a multiplication factor of thermal flux density and thermal resistance values. The temperature drops on low-conductivity thermal insulation layers are high, and on layers construction materials with high thermal conductivity are small. This results directly from the Fourier law. Calculation of the temperature distribution in the partition helps to check the correctness of the arrangement of partition layers.

Considering the above thermal insulation is understood as the elements that reduce the heat flow between indoor and outdoor spaces as well as between spaces of different temperatures. In addition, it ensures a balanced room climate by maintaining a proper wall surface temperature in winter and a pleasant indoor climate in summer. With good insulation, thermal bridges such as connection points to the roof and balcony, concrete lintels, external corners, etc. are no longer weak points of the partition. Thus, ensuring the optimum use of heat accumulation capacity. As it results from the above, the thermal insulation of the building envelope is one of the key factors influencing the energy consumption of the building. In an incorrectly insulated building, heat loss is considered to be as in Figure 1. In times of rising energy costs, the properly selected insulation of a building saves energy and thus contributes to environmental protection. 


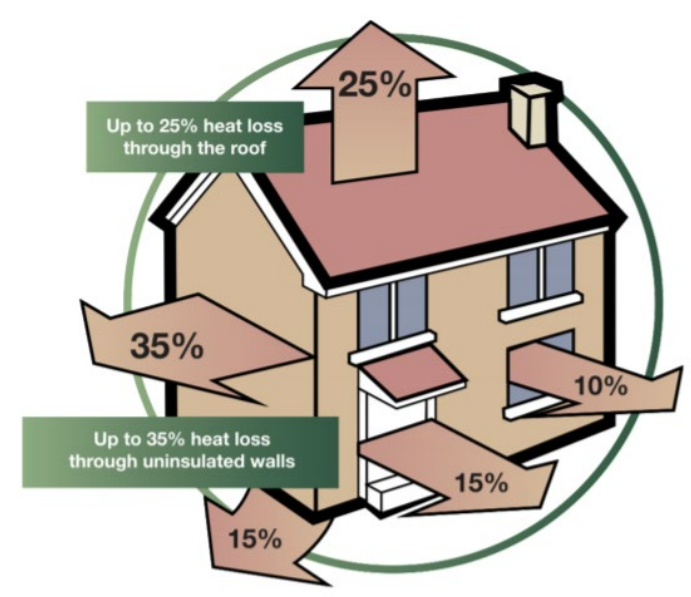

Figure 1. House heat loss diagram [7].

Properly selected insulation of building partitions allows for maintaining thermal comfort. The most optimal parameters in living rooms are temperature in the range of $18-22^{\circ} \mathrm{C}$ and relative air humidity at the level of $40-60 \%$. If the humidity exceeds these limits, it has a negative impact on the mood of people staying in the room. The wall surface temperature or the speed of air movement is equally important. The difference between the room air temperature and the temperature of the surrounding surfaces should not exceed $3{ }^{\circ} \mathrm{C}$. If it is higher, the air cools down quickly that it feels like a draught. The same is true for the convective air movement in the room. It is unnoticeable to humans when the speed is lower than $0.2 \mathrm{~m} / \mathrm{s}$.

When designing a low-energy building, we cannot forget about its proper location in relation to the world sides and the arrangement of the rooms according to the principle of "following the sun". Rooms where people stay in the morning should be placed on the east side, day and evening rooms on the south, south-west and west side, and rooms not requiring direct sunshine on the north side. The shape of the building itself is also important. In the report published by British National House-Building Council in 2016 [8], Form Factor, (expressed by formula 4) describes the efficiency of a building's type and shape. It has a value in the range $0.5-5$. More energy efficient, more compact buildings are those whose shape factor will take lower values. For passive buildings it is accepted that they should reach a value of 3 or less.

$$
\text { Form Factor }=\frac{\text { Total heat loss area of walls,roofs,floors and openings }\left(\mathrm{m}^{2}\right)}{\text { Habitable floor area of all storeys }\left(\mathrm{m}^{2}\right)}
$$

All the above factors influencing a building's energy demand such as the heat transfer coefficient or the shape and location of the building were taken into account in the analysis. 
The second element affecting the energy performance of a building is the use of renewable energy sources. The higher share of renewable energy sources in the annual final energy demand of a building, the more environmentally friendly the building is. Photovoltaicthermal (PV/T) collectors are hybrid solutions for the conversion of solar energy into electrical and thermal energy. By combining PV panel with a thermal collector to form a hybrid photovoltaic-thermal collector, the cells temperature can be reduced by extracting heat through a heat transfer fluid. Therefore, the efficiency of hybrid PVT collector is increased [9]. The main objective of $\mathrm{PV} / \mathrm{T}$ collectors is to use the large part of unused solar energy in conventional photovoltaic (PV) modules for thermal applications [10]. PV/T system with heat pipe technology allowed the recovery of the waste heat form the cooling process and the simultaneous production of electricity and heat [11]. This system can be used in residential buildings, thus reducing the need for energy from non-renewable sources.

In several publications the authors analyse the cooperation of $\mathrm{PV} / \mathrm{T}$ with other installations in order to determine the performance of individual systems. R. Braun et al. [12] analysed trigeneration systems with PV/T collectors for zero energy office buildings in different climates zones (Moscow, Stuttgart, Dubai). M. Herrando et al. [13] used TRNSYS to investigate the technoeconomic performance of solar combined cooling, heating and power (S-CCHP) systems based on hybrid PV/T collectors. In this work [14] the authors analysed a PV/T based solar assisted ground source heat pump system using TRNSYS program. This article [15] reports on the evaluation of the short and long-term electrical performance of a photovoltaic-thermal (PVT) system coupled with borehole thermal energy storage (BTES) for small office in two different climate zones in United States. The results obtained from the simulation by Khordehgah et al. in [16] indicated how much the solar panel is able to convert the solar energy into electrical power and heat over different seasons of the year to provide the domestic hot water needs of a household. In this article, a PV/T integrated system was developed using TRNSYS and energy performance analyses were conducted to discover the functionality of the model under different solar radiation conditions throughout different seasons of the year.

The share of domestic hot water in the total annual energy demand balance in new buildings is much higher than in old buildings with high heat losses. This is due to the fact that the heat demand for DHW is almost constant over the year. However, at all times, the greatest operating cost of a house is still borne by its heating needs. This article will expand the work conducted by Khordehgah et al. [17] of the annual performance analysis of the PV/T system for the heat demand of a low-energy single-family in winter under the climatic conditions of Great Britain 
using TRNSYS software. The authors will investigate the work of the PV/T system which is a heat source for low-temperature mechanical ventilation system for the building.

\section{Model description}

The TRNSYS simulation software was employed to develop and analyse the performance of a photovoltaics-thermal system for single-family building located in London. The capital of the United Kingdom has a temperate warm climate with an average annual temperature of $11.1^{\circ} \mathrm{C}$. TRNSYS stands for TRaNsient System Simulation and allows for development of dynamic simulation to perform analyses on the performance of a system as a function of time or in a transient manner using different variables. The software developed by Wisconsin-Madison University has been designed to simulate the transient behavior of a system through linking different system components or Types as a function of each other. This means that the outputs created by one Type can be used as the input of another component or be plotted as the result of the simulation. The TRNSYS simulation tool has been identified as promising solution for analysing the performance of different solar integrated systems and has been considered in many areas of research [16].

\subsection{Building model description}

Multizone building model (known as Type 56) in a visual interface (TRNBuild) software was used to build a model of a single-family with an unheated attic. It is a singlestorey building on a rectangular plan, with a gable roof (set at an angle of 35 degrees). In order to visualize it, a 3D model of the analysed building was constructed in Skechup software and is presented in Figure 2. Two zones are defined on the ground floor in the building: Sunzone (the main wall is set to the south) and Backzone (the main wall is set to the north). On the south wall there are $5 \mathrm{~m}^{2}$ windows and $4 \mathrm{~m}^{2}$ on the north wall. The construction of the walls takes into account the requirements for the external walls in terms of the coefficient of heat transfer according to UK guidance. Parameters of particular building elements are listed in the Table 2 below. 


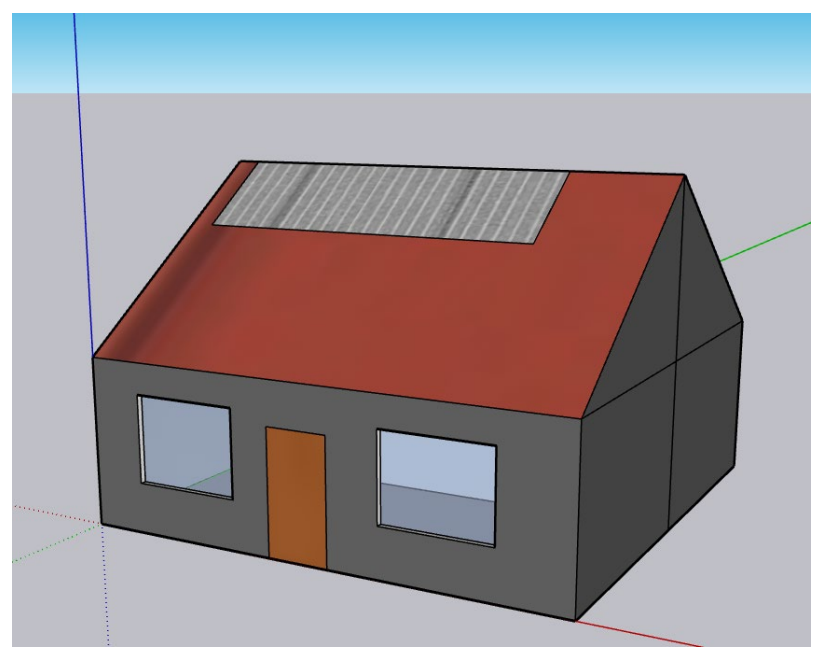

Figure 2. 3D model of the analysed building created in Skechup software.

Table 2. Parameters of particular building elements

\begin{tabular}{|l|c|c|c|}
\hline External walls & Orientation & $\begin{array}{c}\text { Area } \\
{\left[\mathrm{m}^{2}\right]}\end{array}$ & $\begin{array}{c}\mathrm{U} \\
{\left[\mathrm{W} / \mathrm{m}^{2} \mathrm{~K}\right]}\end{array}$ \\
\hline External walls & East/West & $\begin{array}{c}21.6 \\
\text { for each zones } \\
\text { (including } \\
\text { windows) }\end{array}$ & 0.16 \\
\hline Roof & North/South & $\begin{array}{c}16.4 \\
\text { for each zones } \\
\text { for each roof slope }\end{array}$ & 0.16 \\
\hline Flor & - & $\begin{array}{c}32.0 \\
\text { for each zones }\end{array}$ & 0.11 \\
\hline Windows & South & 5 & 0.9 \\
\hline Windows & North & 4 & 0.9 \\
\hline
\end{tabular}

The northern hemisphere was defined in order to compute the correct azimuth angles of surface orientations. In this building model a thermal zone is equal to an airnode. The location of the building is taken into account by applying Type 15-2 (an external weather data file - for London). The model defines: infiltration at a constant level of $0.61 / \mathrm{h}$. First, the room temperature in both defined zones was checked without any source of heat. Then heating was set to maintain a constant temperature of $20^{\circ} \mathrm{C}$ during the winter (without a schedule day/night) and humidity at 50\%. The possibility of room cooling has been turned off. As well as internal gains from people and equipment have been set to 0 to analyse the behaviour of the building itself. 


\subsection{PVT system model description}

For this study as shown in the Table 3 and Figure 3 several TRNSYS Types were used to build and model the system. These configurations allow indicating the effect of cooling of the panel through water circulation as well as transferring heat to a mechanical ventilation system that heats both zones. Controlled splitter is used to model a feedwater splitter. A demanded mass flow input is set as output for outlet 1, the remaining flow is going to outlet two. Outlet temperature 1 and 2 are equal to the inlet temperature. Warm water is fed into two heat exchangers where the air is heated. The warm air is supplied to the relevant zones of the analysed building by a fan. Room thermostat is responsible for maintaining the set temperature at $20^{\circ} \mathrm{C}$ in the Sun and Back zone. Compared to commonly used water heating systems, air heating has a low thermal inertia. After a short heating time, the room temperature (even of considerable cubic capacity) shows changes that can be detected by the thermostat. Additionally in Type11 model uses mode 1 to model a tee piece in which two inlet liquid streams are mixed together into a single liquid outlet stream was modelled. For the configured system, an annual analysis of the work was performed.

Table 2 Components used for the System.

\begin{tabular}{|c|l|}
\hline Type & Name \\
\hline 15 & Weather Data Processor \\
\hline 50 & PV-Thermal Module \\
\hline 4 & Storage Tank \\
\hline 3 & Pump \\
\hline 305 & FW splitter \\
\hline 11 & Tee piece \\
\hline $5 \mathrm{e}$ & Heat exchanger \\
\hline $112 \mathrm{~b}$ & Fan \\
\hline 56 & Building model \\
\hline 108 & Room thermostat \\
\hline
\end{tabular}




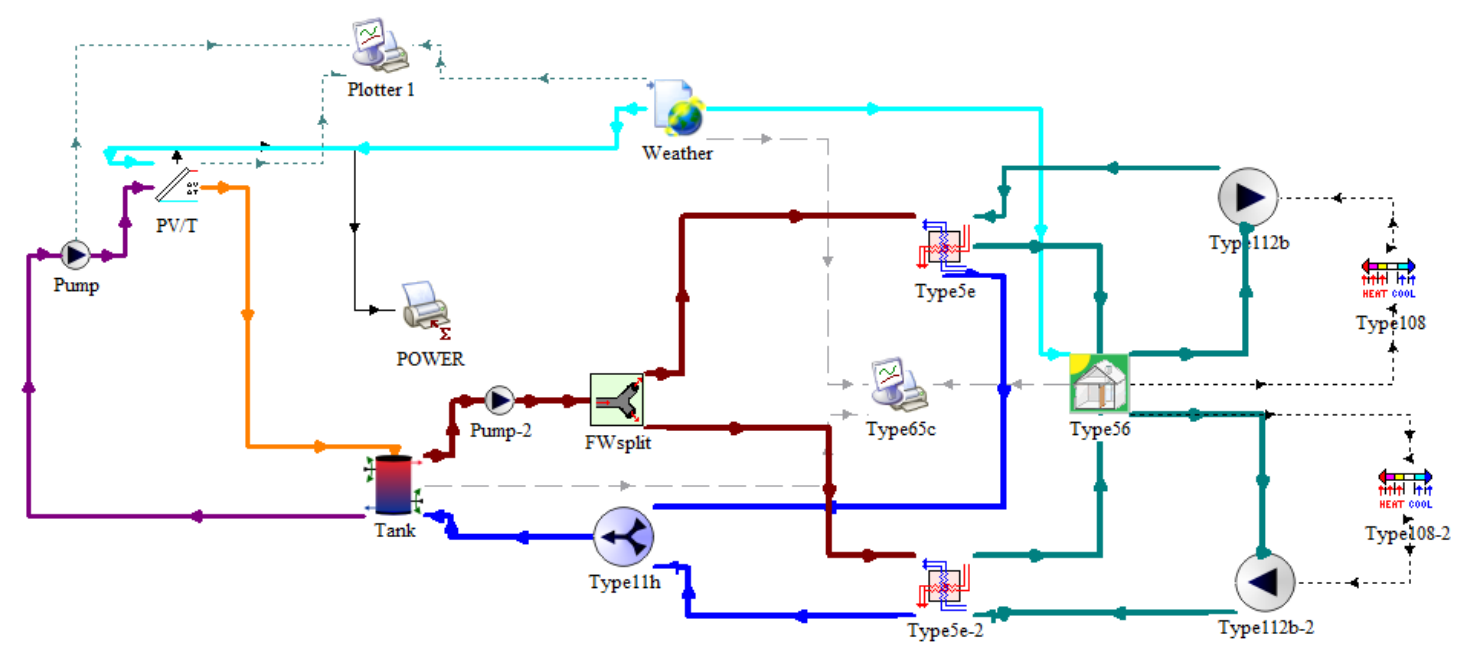

Figure 3. PV/T system in TRNSYS simulation platform.

\section{Results}

The amount of energy required during the year to maintain thermal comfort conditions (a room temperature of $20^{\circ} \mathrm{C}$ ) in each zone was tested separately in two variants using TRNSYS software:

- internal heating system in the Type 56- as a reference building,

- heating as a PVT system with a storage tank and heat exchangers.

\subsection{Internal heating system in the Type 56}

In the first step, it was checked how the room temperature changes in each zone during the year when there is no heating system in the building. With the lowest U-values recommended for new buildings in the UK it is not possible to maintain the room temperature setpoint at $20^{\circ} \mathrm{C}$. The temperature variation in the analysed case is presented in Figure 4. In the analysed zones the lowest ambient temperature $\left(\mathrm{T}_{\mathrm{a}}\right.$ Backzone, $\mathrm{T}_{\mathrm{a}}$ Sunzone) is $4.41^{\circ} \mathrm{C} 4.75^{\circ} \mathrm{C}$ for the Backzone and Sunzone respectively (in 1088 hour of the analysed year) and for operational temperatures ( $\mathrm{T}_{\text {op }}$ Backzone, $\mathrm{T}_{\text {op }}$ Sunzone) it is $4.64^{\circ} \mathrm{C}$ and $4.99^{\circ} \mathrm{C}$ respectively. Temperatures above $20^{\circ} \mathrm{C}$ occur in only $22.2 \%$ of the year. The highest temperatures is $23.87^{\circ} \mathrm{C}$ (in $5557 \mathrm{~h}$ ) and $26.25^{\circ} \mathrm{C}$ (in 5535h) for the Backzone and Sunzone respectively. The average temperature during the year is $13.79^{\circ}$ and $14.39^{\circ} \mathrm{C}$ for the Backzone and Sunzone respectively. 


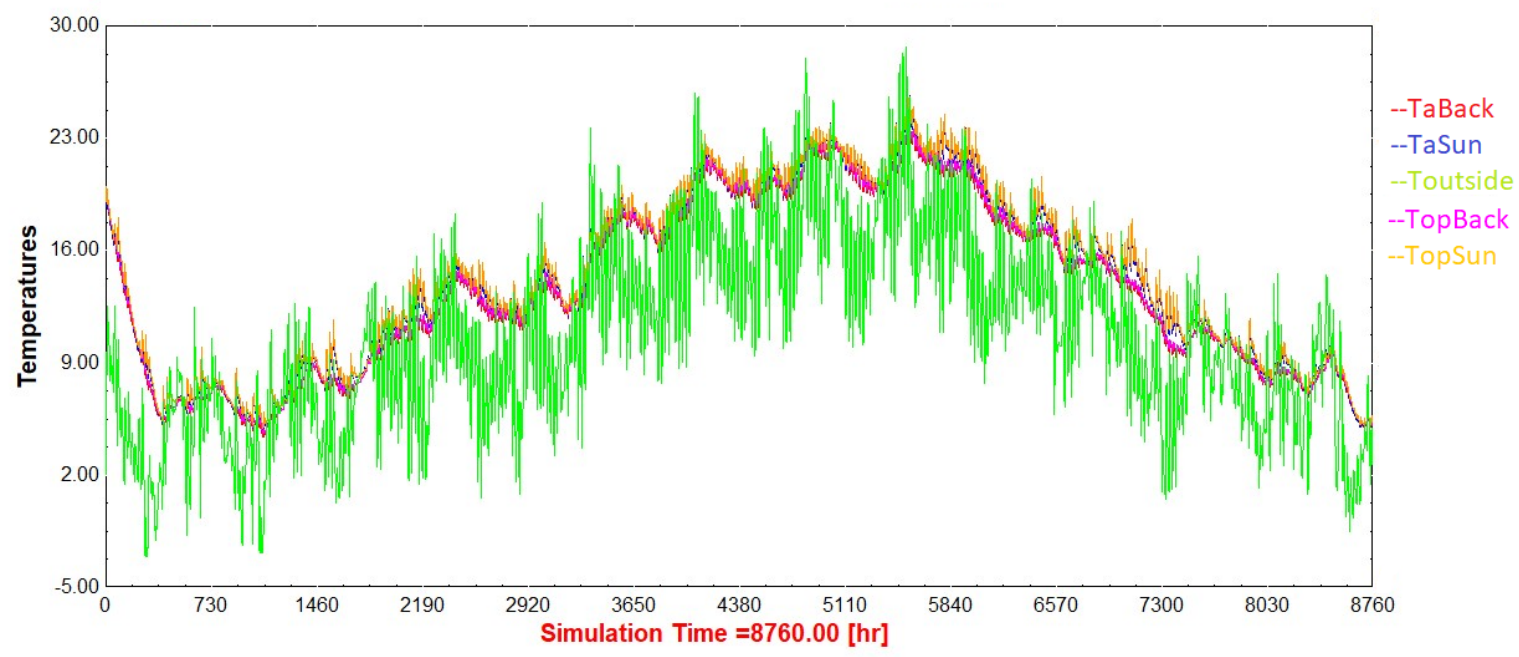

Figure 4. Temperature changes in each zone during the year.

In order to maintain the comfort temperature, it is necessary to switch on the heating system. For this purpose, the room temperature set point in Type 56 is $20^{\circ} \mathrm{C}$ in each zone. Simultaneously, unlimited heating is switched on in order to maintain the set temperature. This setting of the heating system allows checking the maximum amount of heat to be supplied to the rooms depending on the zone. It was found that for the Backzone it is $0.738 \mathrm{kWh}$ and for the Sunzone is $0.757 \mathrm{kWh}$ in $345 / 346$ hour of the year. In order to maintain the set temperature during the year, a total of $2357.24 \mathrm{kWh}$ and $2011.98 \mathrm{kWh}$ to the Back and Sunzone respectively must be supplied (QheatBack, QheatSun). On Figure 5 and Figure 6 temperature changes and heating demand for each zone during the year is presented. 


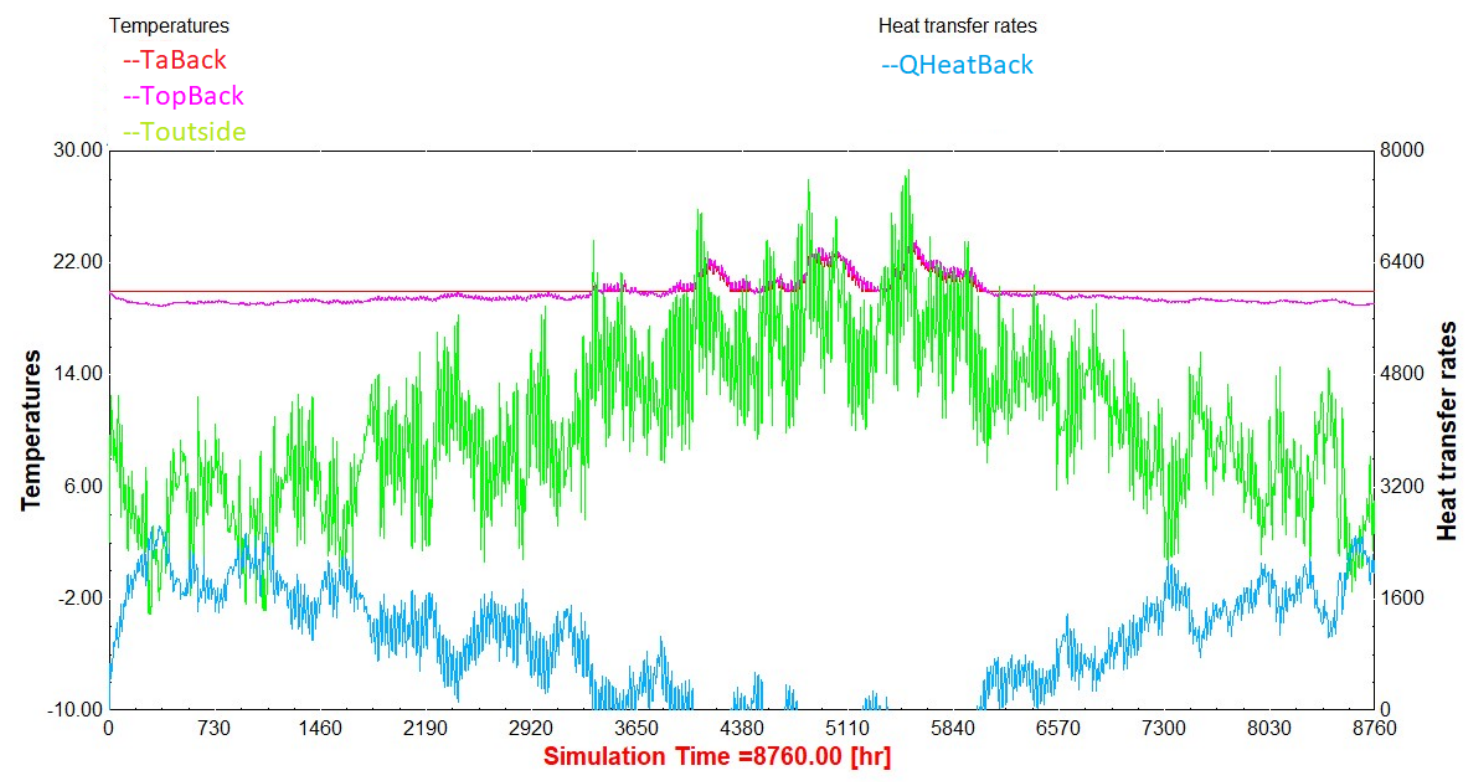

Figure 5. Temperature changes in each zone during the year when the heating system is on in the Backzone. QHeatBack-Heat transfer rates $(\mathrm{kJ} / \mathrm{h})$.

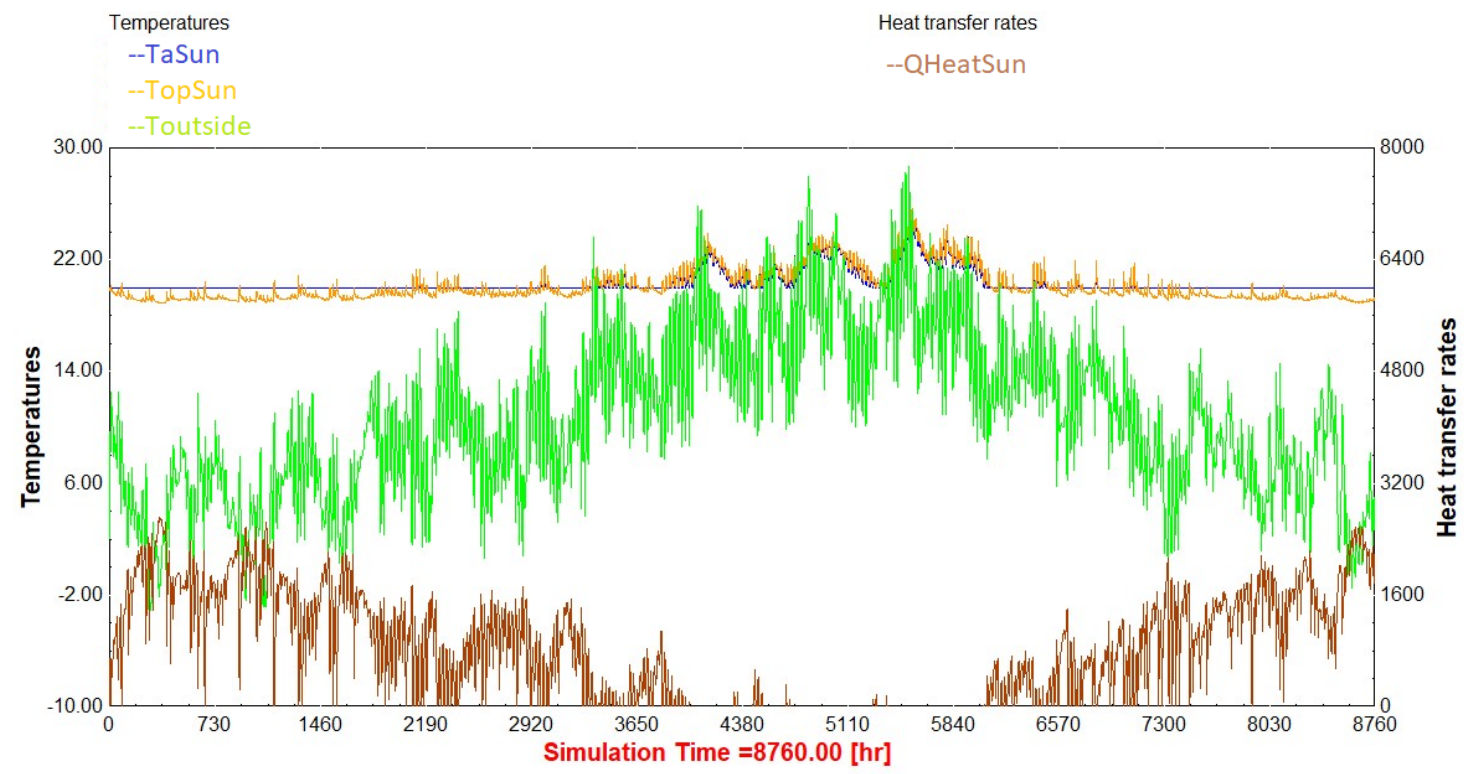

Figure 6. Temperature changes in each zone during the year when the heating system is on in the Sunzone. QHeatSun -Heat transfer rates $(\mathrm{kJ} / \mathrm{h})$. 


\subsection{PVT - external heating system}

The amount of energy supplied from the PVT system to the tank during the year for the examined location - London is analysed. As can be seen in Figure 7 the PTV system is not able to deliver enough energy during the winter to keep the water temperature in the tank at the set level $\left(40^{\circ} \mathrm{C}\right)$. In the analysed latitude, for the first two months of the year and the last three months of the year, the water temperature in a tank does not reach $30^{\circ} \mathrm{C}$ for most of the time. An additional heat source (auxiliary heater) is required. However, during spring and autumn, the PVT system significantly reduces the heat demand of the air system as can be seen in Figure 8. The total annual amount of additional energy needed in the water storage tank (auxiliary heater) is $1548.35 \mathrm{kWh}$. The total annual amount of energy rate to load is $1903.88 \mathrm{kWh}$.

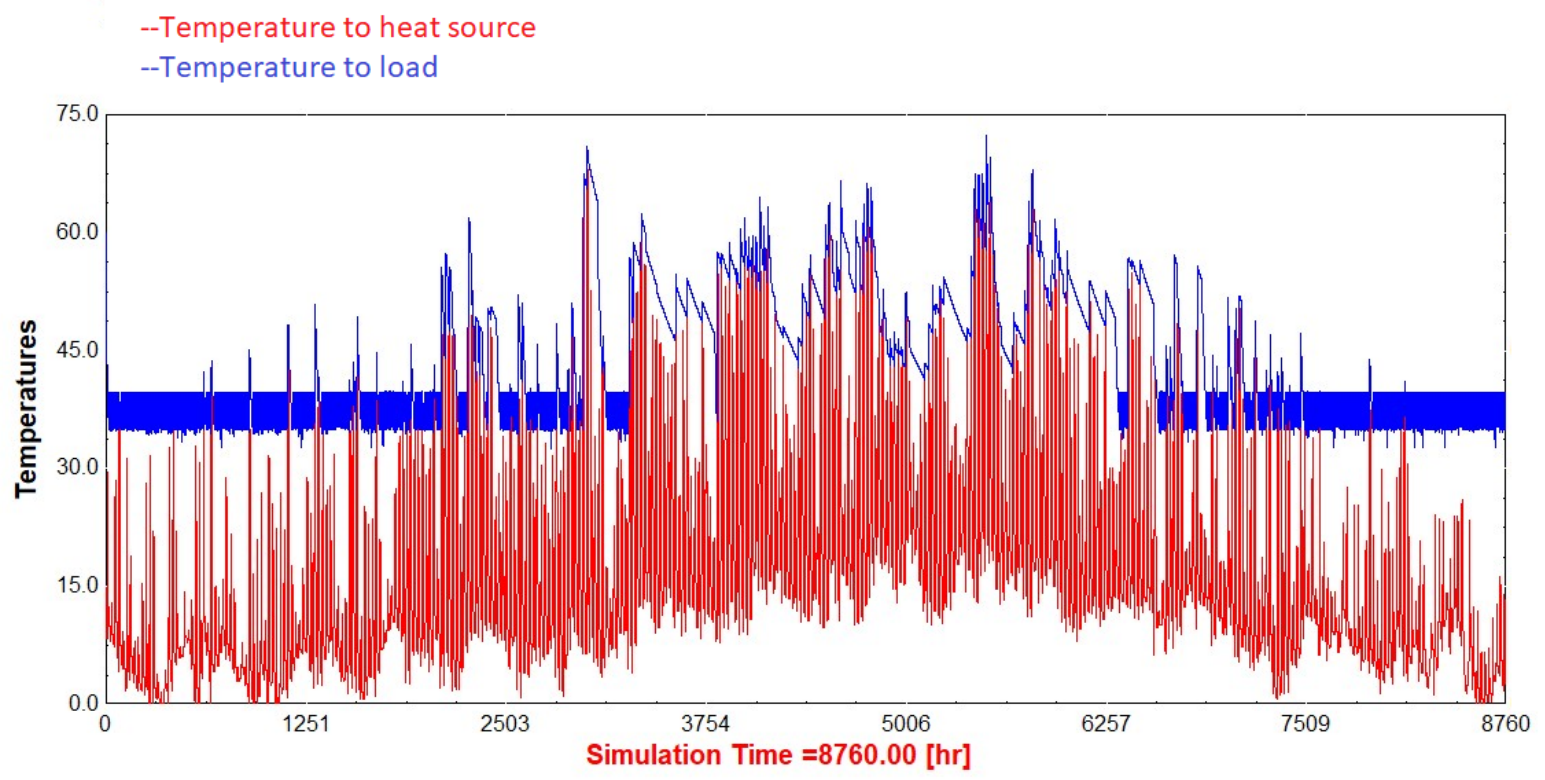

Figure 7. Water temperature at the inlet and outlet of the tank (from PVT system to tank (red line) and from tank to the heat exchanger (blue line) respectively). 


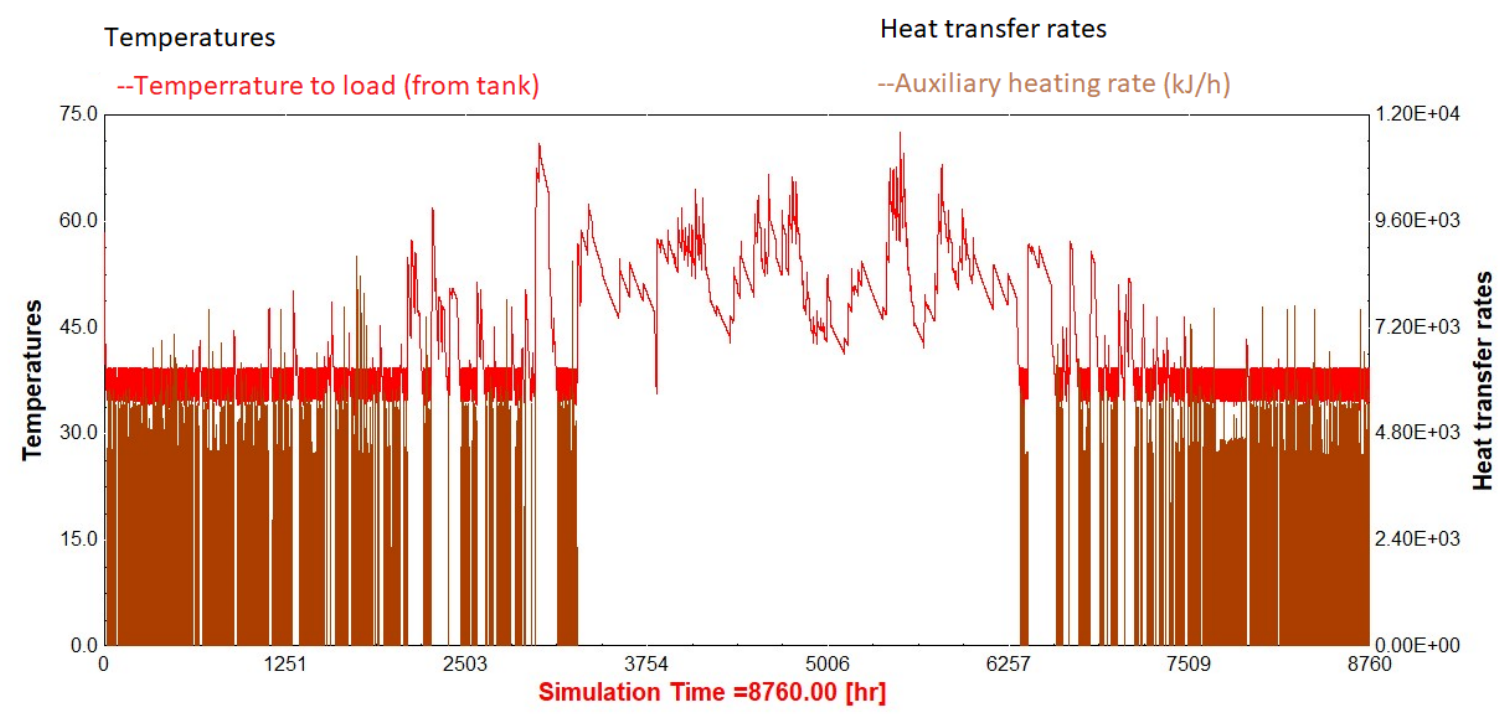

Figure 8. The amount of energy supplied from auxiliary heater located in the storage tank (brawn line).

The temperature variation for each zone (ambient and operational temperatures for Back and Sun zone- $\mathrm{T}_{\text {air }}$ Backzone, $\mathrm{T}_{\text {air }}$ Sunzone, $\mathrm{T}_{\mathrm{op}}$ Backzone, $\mathrm{T}_{\mathrm{op}}$ Sunzone) and the amount of energy supplied to the heat exchanger from the tank are shown in Figure 9. It is worth noting that the temperature in the zones has not fallen below the $18^{\circ} \mathrm{C}$ setpoint over the entire period under consideration according to the hysteresis set on the thermostat. During the summer, the difference in maximum temperature in the Back and Sun zones is negligible as it is $0.04^{\circ} \mathrm{C}$.

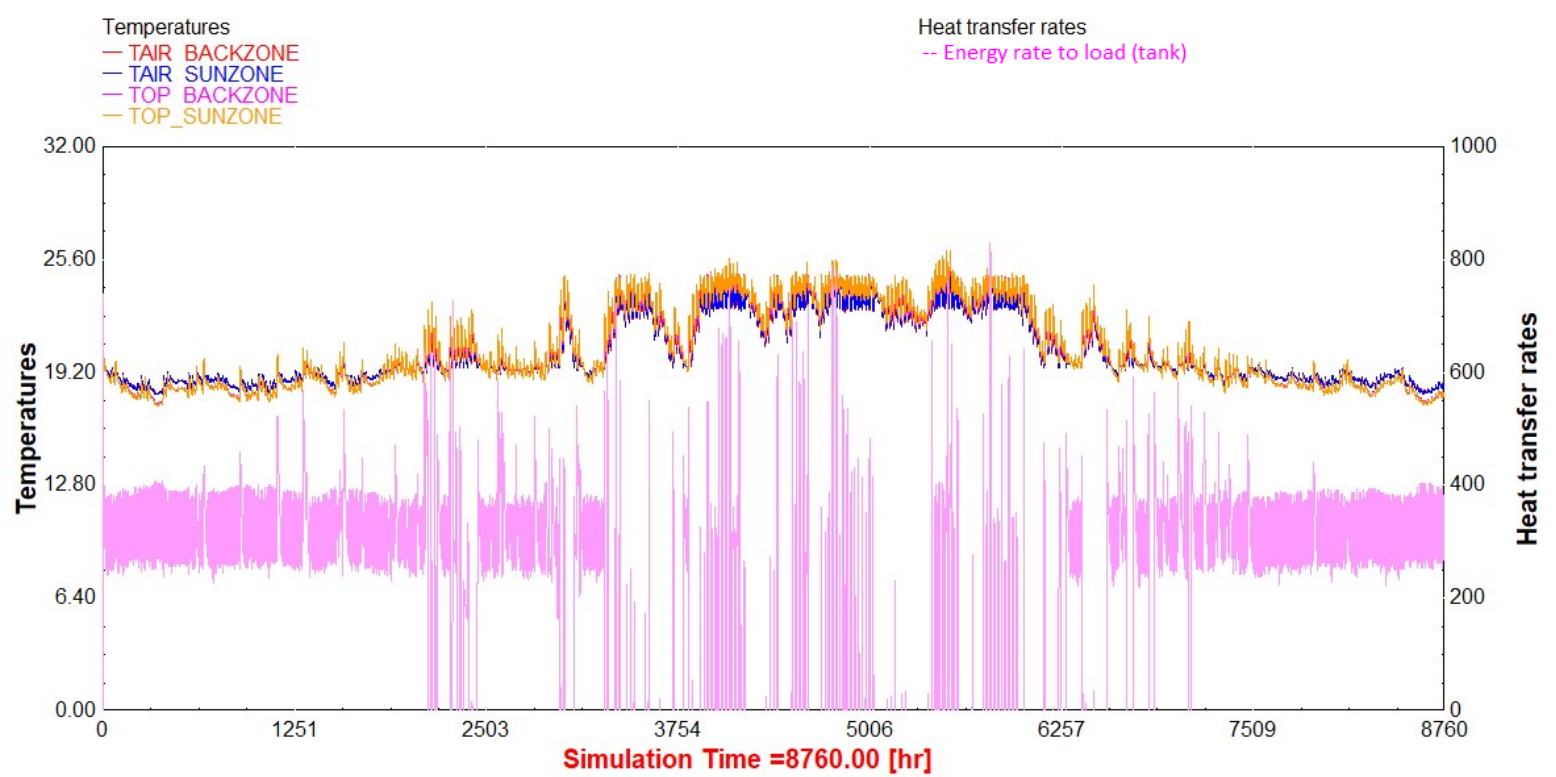

Figure 9. The temperature variation for each zone and the amount of energy supplied to the heat exchanger from the tank $(\mathrm{kJ} / \mathrm{h})$. 


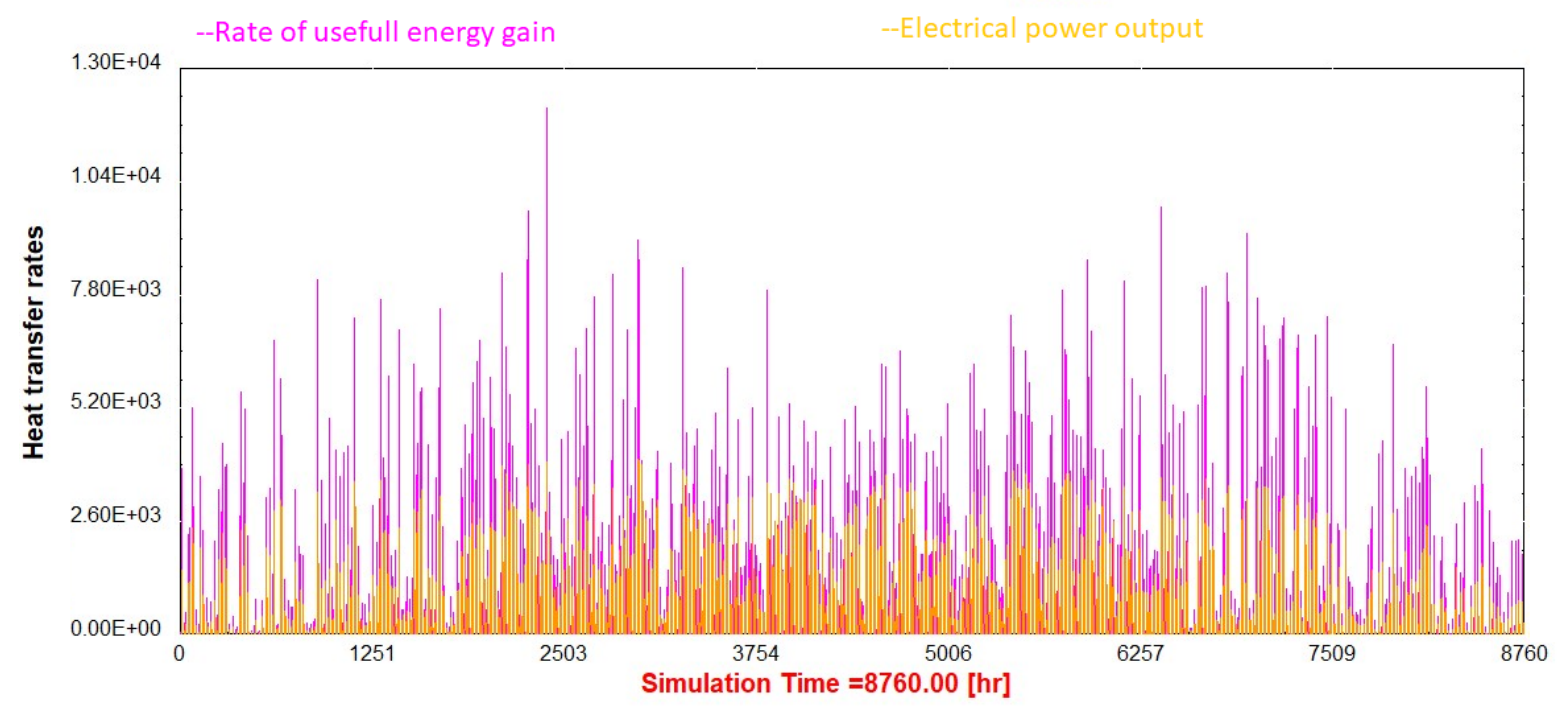

Figure 10. Rate of useful energy gain and electrical power output from PV/T.

Rate of useful energy gain and electrical power output from PV/T is presented in Figure 10. Total rate at which electrical energy is generated by the PV section of the collector during a year is $4048.23 \mathrm{kWh}$. Total rate at which energy is added to the liquid stream is $1493.30 \mathrm{kWh}$. For the first 3 months and last 3 months of the year, PV/T generates $388.20 \mathrm{kWh}$ and $256.23 \mathrm{kWh}$ useful energy gain and $1067.960 \mathrm{kWh}$ and $558.03 \mathrm{KWh}$ of electrical energy respectively.

\section{Conclusions}

Solar energy is a source of energy with high potential that can significantly reduce the need for heat in buildings by improving their energy efficiency and reducing their operating costs. The only disadvantage is the lack of a continuous supply of energy throughout the year adapted to the needs of the users.

In the article, an annual performance analysis of the PVT system, which is a heat source for mechanical ventilation heating system for a single-family building, was conducted. In TRNSYS software, using Type 56, the authors built a model of a low energy building. The temperature variability in individual zones and their annual heat demand were analysed. It was found that with a PV/T panel surface of $12 \mathrm{~m}$, it is not possible to maintain a comfort temperature of $20^{\circ} \mathrm{C}$ in the room during the winter without an additional source of heat. However, during spring and autumn, the PVT system significantly reduces the heat demand of the air system. Looking at the results of the simulation, it should be noted that the application under consideration - PV/T 
working with an air system for heating during the winter period is not energy-optimal solution. The amount of heat and electricity generated by a PVT system during the summer would have to be integrated into a long-term (seasonal) energy storage system so that it could be used in periods with less insolation or as a lower heat source for the heat pump. It was concluded that further analyses of the cooperation of the PV/T system with other building heating systems are necessary in order to find the most energy-optimal solution for heating building.

\section{Acknowledgements}

The report has been receiving financial support from the Innovation and Networks Executive Agency (INEA), European Commission for project PVadapt under Grant Agreement number 818342.

\section{References}

[1] Eurostat, "Energy statistics - an overview," Eurostat Off. Website, vol. 2016, no. July 2018, pp. 1-22, 2019.

[2] Official Journal of the European Union, "DIRECTIVE (EU) 2018/844 OF THE EUROPEAN PARLIAMENT AND OF THE COUNCIL of 30 May 2018 amending Directive 2010/31/EU on the energy performance of buildings and Directive 2012/27/EU on energy efficiency," Off. J. Eur. Union, vol. L 156/75, 2018, doi: 10.1007/3-540-47891-4_10.

[3] EUROPEAN COMMISSION, “COM(2011) 885 final. Energy Roadmap 2050,” vol. 11, no. 2, pp. 10-14, 2011, doi: 10.16194/j.cnki.31-1059/g4.2011.07.016.

[4] CIBSE, GVA/15 CIBSE Guide A: Environmental Design 2015. 2015.

[5] Journal of Laws of the Republic of Poland, "Regulation of the Minister of Infrastructure of 12 April 2002 on the Technical Specifications for Buildings and Their Location.," pp. 1-112, 2019.

[6] International organization for standardization, "ISO 6946:2017 - Building components and building elements - Thermal resistance and thermal transmittance," Int. Organ. Stand. Geneva, Switz., 2017.

[7] O. Kyle and G. Selim, "Prefab (and preserve): An investigation of retrofitting for Belfast's Victorian terraced social housing," J. Build. Surv. Apprais. Valuat., vol. 4, no. 1, pp. 63-77, 2015. 
[8] NHBC, The challenge of shape and form Understanding the benefits of efficient design. 2016.

[9] M. Hissouf, M. Feddaoui, M. Najim, and A. Charef, "Numerical study of a covered Photovoltaic-Thermal Collector ( PVT ) enhancement using nano fl uids," Sol. Energy, vol. 199, no. August 2019, pp. 115-127, 2020, doi: 10.1016/j.solener.2020.01.083.

[10] D. Jonas, M. Lämmle, D. Theis, S. Schneider, and G. Frey, "Performance modeling of PVT collectors: Implementation, validation and parameter identification approach using TRNSYS," Sol. Energy, vol. 193, no. September, pp. 51-64, 2019, doi: 10.1016/j.solener.2019.09.047.

[11] H. Jouhara et al., "The performance of a heat pipe based solar PV/T roof collector and its potential contribution in district heating applications," Energy, vol. 136, pp. 117125, 2017, doi: 10.1016/j.energy.2016.04.070.

[12] R. Braun, M. Haag, J. Stave, N. Abdelnour, and U. Eicker, "System design and feasibility of trigeneration systems with hybrid photovoltaic-thermal (PVT) collectors for zero energy office buildings in different climates," Sol. Energy, vol. 196, no. March 2019, pp. 39-48, 2020, doi: 10.1016/j.solener.2019.12.005.

[13] M. Herrando, A. M. Pantaleo, K. Wang, and C. N. Markides, "Solar combined cooling, heating and power systems based on hybrid PVT, PV or solar-thermal collectors for building applications," Renew. Energy, vol. 143, pp. 637-647, 2019, doi: 10.1016/j.renene.2019.05.004.

[14] E. I. Sakellariou, A. J. Wright, P. Axaopoulos, and M. A. Oyinlola, "PVT based solar assisted ground source heat pump system: Modelling approach and sensitivity analyses," Sol. Energy, vol. 193, no. September, pp. 37-50, 2019, doi: 10.1016/j.solener.2019.09.044.

[15] M. Aldubyan and A. Chiasson, "Thermal Study of Hybrid Photovoltaic-Thermal (PVT) Solar Collectors Combined with Borehole Thermal Energy Storage Systems," Energy Procedia, vol. 141, pp. 102-108, 2017, doi: 10.1016/j.egypro.2017.11.020.

[16] N. Khordehgah, V. Guichet, S. P. Lester, and H. Jouhara, "Computational study and experimental validation of a solar photovoltaics and thermal technology," Renew. Energy, vol. 143, pp. 1348-1356, 2019, doi: 10.1016/j.renene.2019.05.108. 
[17] N. Khordehgah, A. Żabnieńska-Góra, and H. Jouhara, "Energy Performance Analysis of a PV/T System Coupled with Domestic Hot Water System," ChemEngineering, vol. 4, no. 2, p. 22, 2020, doi: 10.3390/chemengineering4020022. 